\title{
PREVISÃO DE DADOS DE ALTA FREQUÊNCIA PARA CARGA ELÉTRICA USANDO HOLT-WINTERS COM DOIS CICLOS
}

Dissertação apresentada ao Programa de Pósgraduação em Engenharia Elétrica da PUC-Rio como requisito parcial para obtenção do título de Mestre em Engenharia Elétrica: Métodos de Apoio à Decisão.

Orientador: Prof. Reinaldo Castro Souza 


$$
\text { Pontifícia } U_{\text {Niversidade }} \text { Católica }_{\text {Do Rio de Janeiro }}
$$

\section{Cristina Vidigal Cabral de Miranda}

\section{PREVISÃO DE DADOS DE ALTA FREQUÊNCIA PARA CARGA ELÉTRICA USANDO HOLT-WINTERS COM DOIS CICLOS}

Dissertação apresentada como requisito parcial para obtenção do grau de Mestre pelo Programa de PósGraduação em Engenharia Elétrica do Departamento de Engenharia Elétrica da PUC-Rio. Aprovada pela Comissão Examinadora abaixo assinada.

Prof. Dr. Reinaldo Castro Souza

Orientador

Departamento de Engenharia Elétrica - PUC-Rio

Profa. Dra. Marley Maria B. Rebuzzi Vellasco

Departamento de Engenharia Elétrica - PUC-Rio

Dr. Plutarcho Maravilha Lourenço

CEPEL

Dr. Juan Guillermo Lazo Lazo

Departamento de Engenharia Elétrica - PUC-Rio

Profa. Dr. Mônica Barros

Departamento de Engenharia Elétrica - PUC-Rio

Prof. José Eugenio Leal

Coordenador Setorial do Centro

Técnico Científico

Rio de Janeiro, 22 de março de 2007 
Todos os direitos reservados. É proibida a reprodução total ou parcial do trabalho sem autorização da universidade, da autora e do orientador.

\section{Cristina Vidigal Cabral de Miranda}

Graduou-se em Ciências Econômicas na Universidade Federal de Juiz de Fora (UFJF) em 2003. Especializou-se em Métodos Estatísticos Computacionais na UFJF em 2004.

Ficha Catalográfica

Miranda, Cristina Vidigal Cabral de

Previsão de dados de alta-freqüência para carga elétrica usando Holt-Winters com dois ciclos / Cristina Vidigal Cabral de Miranda ; orientador: Reinaldo Castro Souza. - 2007.

114 f. : il. ; $30 \mathrm{~cm}$

Dissertação (Mestrado em Engenharia Elétrica)Pontifícia Universidade Católica do Rio de Janeiro, Rio de Janeiro, 2007.

Inclui referências bibliográficas.

1. Engenharia elétrica - Teses. 2. Previsão para dados de alta freqüência. 3. Método de Holt-Winters com dois ciclos. 4. Feriado. 5. Temperatura. I. Souza, Reinaldo Castro. II. Pontifícia Universidade Católica do Rio de Janeiro. Departamento de Engenharia Elétrica. III. Título. 


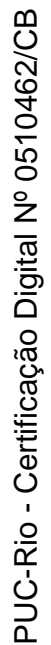

Este trabalho é dedicado aos meus pais,

João e Rosângela, pelo apoio e confiança. 


\section{Agradecimentos}

Ao meu orientador, Prof. Reinaldo Castro Souza, pela ajuda e pela confiança.

A Ana Paiva e ao Alexandre Zanini por terem me apoiado deste o momento em que cheguei aqui.

A todos os professores com os quais tive aula, pelos seus ensinamentos. À profa. Mônica Barros, por todos os ensinamentos durante esse trabalho.

Aos meus pais, por todo amor, carinho e pela força nos momentos de dificuldade.

À minha irmã Fernanda, pelo apoio, carinho e ajuda.

Ao Eduardo por estar sempre ao meu lado.

À minha família, por sempre torcer por mim.

A todos os amigos que conheci aqui e que sempre me deram força. 


\section{Resumo}

Miranda, Cristina Vidigal Cabral de; Souza, Reinaldo Castro. Previsão de Dados de Alta Freqüiência para Carga Elétrica usando Holt-Winters com Dois Ciclos. Rio de Janeiro, 2007. 112p. Dissertação de Mestrado Departamento de Engenharia Elétrica, Pontifícia Universidade Católica do Rio de Janeiro.

A previsão para dados de alta frequiência é fundamental para a segurança e confiabilidade da operação do sistema elétrico. Os métodos de amortecimento exponencial, em particular o método de Holt-Winters e suas variações, são apropriados para este contexto devido à sua alta adaptabilidade e robustez. Este trabalho visa à previsão a cada quinze minutos para sete dias à frente, isto é, 672 passos à frente, para dados de energia elétrica de uma concessionária da região sudeste do Brasil. Para tanto, será utilizado o método de Holt-Winters com dois ciclos, que foi proposto recentemente por J. Taylor. Além disso, será incluído o tratamento de feriados e a influência da temperatura, que serão aplicadas de forma exógena ao modelo.

\section{Palavras-chave}

Previsão para dados de alta frequiência, Método de Holt-Winters com dois ciclos, feriado, temperatura. 


\section{Abstract}

Miranda, Cristina Vidigal Cabral de; Souza, Reinaldo Castro (Advisor). Forecasting High Frequency Load Data Using A Double Cycle Holt Winters Approach. Rio de Janeiro, 2007. 112p. Master Dissertation Electrical Engineering Department, Pontifícia Universidade Católica do Rio de Janeiro.

The forecast for high frequency data is fundamental for the safety and reliability of the electric power system operation. The methods of exponential smoothing, particularly the Holt-Winters approach and its variations, are appropriate for this type of data due to its highly adaptability and robustness. This work seeks to produce forecasts, every fifteen minutes, for a time horizon of seven days ahead, that is, 672 steps of fifteen minutes ahead, for a brazilian load series of an important distribution utility located in the southeast region of the country. It is considered the two-cycle version of the Holt-Winters approach as proposed recently by J. Taylor, including some improvements, such as, the treatment of bank holidays and the influence of temperature, acting as exogenous inputs.

\section{Keywords}

Load forecast for high frequency data, double seasonal exponential smoothing methods, bank holidays, temperature 


\section{SUMÁRIO}

1 Introdução

2. Revisão Bibliográfica 18

2.1. Introdução 18

2.1.1. Série Temporal 18

2.1.2. Processo Estocástico 20

2.1.3. Previsão de Séries Temporais 21

2.2. Método Ingênuo (NAÍVE) 23

2.3. Média Móvel 24

2.4. Métodos de Amortecimento Exponencial 25

2.4.1. Métodos de Amortecimento de Brown 26

2.4.2. Métodos de Amortecimento de Holt 27

2.4.3. Métodos de Amortecimento de Holt-Winters 28

2.5. Método de Amortecimento Direto 30

2.6. Modelo de Box \& Jenkins 33

2.6.1. Modelos Box \& Jenkins com Sazonalidade: SARIMA 34

2.7. Modelo de Decomposição de Gupta 35

2.7.1. Modelo para a Carga Padrão 36

2.7.2. Modelo para as variáveis climáticas 37

2.8. Regressão Dinâmica 38

2.9. Redes Neurais 40

2.10. Lógica Fuzzy 43

3. MODELO PROPOSTO 45

3.1. A Extensão do Modelo de Holt-Winters Padrão 45

3.1.1. Holt-Winters com Dois Ciclos 46

3.2. Inicialização dos parâmetros 48 
3.3. Estimação das Constantes de Amortecimento 52

3.4. Tratamento de Feriado 53

3.5. Influência da Temperatura 62

4. Aplicação do Modelo e Resultados 72

4.1. Uso do Holt-Winters com dois ciclos

4.2. Aplicação dos fatores de correção para feriado 87

4.2.1. Resultado dos fatores de correção para feriado 95

4.3. Aplicação do fator de correção para temperatura 98

5. Conclusão 102

5.1. Sugestões 103

6. Referências Bibliográficas 105

Anexo A. Algoritmo Genético 108

A.1. Representação 111

A.2. Codificação e Decodificação 111

A.3. Inicialização da População 111

A.4. Avaliação 112

A.5. Operadores Genéticos 112

A.6. Parâmetros da Evolução 113 


\section{Lista de Figuras}

Figura 2.01 - Exemplo da componente tendência e sazonalidade 28

Figura 2.02 - Geração de uma série temporal 33

Figura 2.03 - Análise de uma série temporal 33

Figura 2.04 - Modelo de um neurônio artificial 41

Figura 2.05 - Sistema de Lógica Fuzzy 43

Figura 3.01 - Curva de demanda elétrica a cada quinze minutos $\quad 45$

de 1 maio/2006 (segunda-feira) a 31 de maio/2006 (quarta-feira)

Figura 3.02 - Demanda de carga elétrica em uma semana que 54

ocorreu um feriado e em uma semana onde não houve feriado

Figura 3.03 - Feriado de Carnaval (ocorreu dia 08/02) 55

Figura 3.04 - Feriado do Natal $\quad 55$

Figura 3.05 - Feriado do Ano Novo 56

Figura 3.06 - Exemplo da Influência da Temperatura sob o 64 Consumo na Espanha

Figura 3.07 - Exemplo da Influência da Temperatura sob o 65 Consumo no Brasil

Figura 3.08 - Modelo da curva de impacto da temperatura no

consumo de energia elétrica

Figura 4.01 - Carga a cada quinze minutos de todo o histórico

Figura 4.02 - Carga a cada quinze minutos de um trimestre 73

Figura 4.03 - Carga a cada quinze minutos de um mês 73

Figura 4.04 - Carga a cada quinze minutos de uma semana $\quad 74$

Figura 4.05 - Carga a cada quinze minutos de um dia 74

Figura 4.06 - Temperatura Máxima e Mínima diária de todo o 75 histórico

Figura 4.07 - Fatores sazonais iniciais para o mês de fevereiro de 
Figura 4.08 - Demanda prevista e realizada para 1 a 7 de 78 fevereiro de 2006

Figura 4.09 - Média dos MAPEs diários 79

Figura 4.10 - Média dos MAPEs horários $\quad 79$

Figura 4.11 - APE da previsão usando Holt-Winters com 2 ciclos $x \quad 80$ da previsão usando modelo NAIVE

Figura 4.12 - Fatores sazonais iniciais para o mês de abril de 80 2006

Figura 4.13 - Demanda prevista e realizada para 1 a 7 de abril de 2006

Figura 4.14 - Média dos MAPEs diários 81

Figura 4.15 - Média dos MAPEs horários 82

Figura 4.16 - APE da previsão usando Holt-Winters com 2 ciclos $x \quad 82$ da previsão usando modelo NAIVE

Figura 4.17 - Fatores sazonais iniciais para o mês de julho de 83 2005

Figura 4.18 - Demanda prevista e realizada para 15 a 21 de julho de 2005

Figura 4.19 - Média dos MAPEs diários 84

Figura 4.20 - Média dos MAPEs horários $\quad 84$

Figura 4.21 - APE da previsão usando Holt-Winters com 2 ciclos x $\quad 84$ da previsão usando modelo NAIVE

Figura 4.22 - Fatores sazonais iniciais para o mês de setembro de $\quad 85$ 2005

Figura 4.23 - Demanda prevista e realizada para 1 a 7 de 85 setembro de 2005

Figura 4.24 - Média dos MAPEs diários 86

Figura 4.25 - Média dos MAPEs horários 86

Figura 4.26 - APE da previsão usando Holt-Winters com 2 ciclos x $\quad 87$

APE da previsão usando modelo NAIVE

Figura 4.27 - Feriado em uma segunda-feira 88

Figura 4.28 - Feriado em uma terça-feira 88

Figura 4.29 - Feriado em uma quarta-feira $\quad 89$ 
Figura 4.30 - Feriado em uma quinta-feira $\quad 89$

Figura 4.31 - Feriado em uma sexta-feira 90

Figura 4.32 - Feriado em um sábado 90

Figura 4.33 - Feriado de Carnaval $\quad 91$

Figura 4.34 - Feriado de Natal em um domingo 91

Figura 4.35 - Feriado de Natal em um sábado 92

Figura 4.36 - Feriado de Natal em uma quarta-feira 92

Figura 4.37 - Feriado de Natal em uma quinta-feira 93

Figura 4.38 - Feriado de Ano Novo em um domingo 93

Figura 4.39 - Feriado de Ano Novo em um sábado 94

Figura 4.40 - Feriado de Ano Novo em uma quarta-feira 94

Figura 4.41 - Feriado de Ano Novo em uma quinta-feira 95

Figura 4.42 - Previsão sem e com correção do feriado - 7 de 96 setembro

Figura 4.43 - Previsão sem e com correção do dia antes do 96 feriado -6 de setembro

Figura 4.44 - Previsão sem e com correção do dia após do feriado $\quad 97$

-8 de setembro

Figura 4.45 - Previsão sem e com correção do feriado - 14 de abril $\quad 97$

Figura 4.46 - Previsão sem e com correção do dia após o feriado - $\quad 98$ 15 de abril

Figura A.01 - Estrutura básica de um algoritmo genético 110

Figura A.02 - Crossover de um ponto 112

Figura A.03 - Mutação 113 


\section{Lista de Tabelas}

Tabela 4.01 - Resultados da aplicação da regra para temperatura 99 máxima para fevereiro 2006

Tabela 4.02 - Resultados da aplicação da regra para temperatura 99 mínima para fevereiro 2006

Tabela 4.03 - Resultados da aplicação da regra para temperatura 100 máxima para setembro 2005

Tabela 4.04 - Resultados da aplicação da regra para temperatura 100 mínima para setembro 2005

Tabela 4.05 - Resultados da aplicação da regra para temperatura 100 mínima para abril 2006

Tabela 4.06 - Resultados da aplicação da regra para temperatura 101 máxima para maio 2005

Tabela 4.07 - Resultados da aplicação da regra para temperatura 101 mínima para maio 2005 